\title{
Understanding the Changing Role of the Management Accountant in the Age of Industry 4.0 in Germany
}

\author{
Rafi Wadan \\ University of Osnabrueck \\ Osnabrueck, Germany \\ rafi.wadan@gmail.com \\ Frank Teuteberg \\ University of Osnabrueck \\ Osnabrueck, Germany \\ frank.teuteberg@uni-osnabrueck.de
}

\author{
Frank Bensberg \\ Hochschule of Osnabrueck \\ Osnabrueck, Germany \\ f.bensberg@hs-osnabrueck.de \\ Gandalf Buscher \\ Hochschule für Telekommunikation Leipzig \\ Leipzig, Germany \\ Gandalf.Buscher@hft-leipzig.de
}

\begin{abstract}
Currently, business processes are undergoing a transformation through digitalization. In the course of this development, "Industry 4.0" also has an impact on management accounting and IT systems. By promising technical development and improvement of management accounting processes, the conventional roles are challenged and the introduction of new occupational fields is prognosticated. However, in theory and practice, the impact of industry 4.0 (I4.0) on management accounting has not been considered adequately so far. Against this background, the primary goal of this study is to investigate the implications of I4.0 on management accounting by means of a triangulation approach. The results of expert interviews, a literature review and an analysis of job advertisements provide an overview on the development of competencies of Management Accountants (MA) in Germany. The results have highlighted a closer cooperation of MA and Data Scientists. Additionally, there will be a shift from traditional analysis towards statistical analysis methods.
\end{abstract}

\section{Introduction}

"Industry 4.0" (smart manufacturing, industrial internet of things, industrie du futur, Industrial Internet Consortium) is currently used in the scientific and economic context as a synonym for the increasing digitization and automation of production systems from humans and machines as well as their networking among themselves [1]. "Plattform Industrie 4.0" [22] defines I4.0 as: "[...] availability of all relevant information in real-time through the networking of all instances involved in value creation as well as the ability to derive the best possible value stream from data at all times." In general, the goal is an efficient, flexible and individual production through completely digitally controlled value chains [24]. The convergence of the digital and manufacturing industries is the key to increase the efficiency of product life cycles and for enabling new business potentials and models [2]. On closer examination, it can be said that the application of I4.0 has been tackled at a technological level so far, and a meaning for people, processes and society as well as their economic impact is weakly illuminated [3]. A survey published by PricewaterhouseCoopers $(\mathrm{PwC})$ on this subject in Germany in 2016, shows that companies can expect direct revenue growth and cost reductions from digitization [4]. However, the current literature also shows that in addition to the overpowering of large infrastructure issues, adaptations in business management are also necessary [5], [6], [7], [8]. The increase in complexity due to comprehensive networking and digitization requires new forms of management accounting to successfully meet tomorrow's challenges. The central reason for this is the fact that the use of digital technologies generally leads to an increasing availability of a great variety of information about ongoing processes. Information is increasingly gaining importance as a production factor for the economy. Already today, companies are facing the challenge of sifting information out of the vast ocean of data for new information and opening up new data sources. The MA as a navigator for the company management is therefore more than ever in demand, the management to point the right course on these topics. At the same time I4.0 offers the MAs new opportunities and tools for better task performance. Especially jobs with a high repetitive character have a high probability of automation, while all those jobs 
where a high adaptability to the customer's needs is required continue to be performed manually [9]. The impact on management accounting is related to the activities and competencies of MA. Its understanding of roles includes a shift in tasks from a pure analyst to a management consultant, i.e. tasks that are difficult to adopt through automation, even as digitization increases. To address this challenge, studies have examined the impact of the digitalization phase on competencies for employees. Erol et al. propose, based on a scenario-based learning concept, that behavioral skills like e.g. communication and intercultural competencies are important for I4.0. Besides that, the necessity to apply and use the technology requires IT and technology affinity (e.g. business process, modelling and programming knowledge) [10]. Acatech, Fraunhofer Institut GmbH analyzed German companies by following a holistic approach and propose a set of competencies which companies should master, and employees should adapt. They highlight social skills like collaboration, customer orientation and competencies to solve problems. In addition to that, they point out that possessing knowledge of cloud computing, artificial intelligence and robotics are crucial [11]. Prifti et al. analyzed that decision making and team working on the soft skills perspective and technical knowledge in big data and predictive tools are required competencies for employees with higher education in the Age of I4.0 in the field of Information Systems, Engineering and Computer Science [12]. Kagermann, one of the leading representatives of I4.0, emphasizes that in the future employees will be used less as "machine operators", "but more in the role of the decision-maker and coordinator" [1]. However, even when these mentioned researchers have incorporated the impact of the current digitalization phase on competencies and roles of employees, the term of management accounting and its changing role through the digitalization phase I4.0 were not researched. Nevertheless, published research in context of changing competences in management accounting has steadily increased over recent decades [13], [14], [15]. Scholars have evaluated new MA techniques such as profitability analysis or strategic pricing, which require stronger coordination and knowledge sharing tasks. In order to execute these tasks, competences in coordination, strategic thinking and system knowledge are required and will shift the MAs therefore more into a business partnering role [16], [17]. Other studies evaluated that IT/system knowledge will be among the predominantly required MA skills, while broad business knowledge and interpretive skills will remain relevant [17]. As a result of this development, new job profiles are being developed which combine economic and information technology competences. Latest research in management accounting regarding the changing role of MAs through a new system was based on the adoption of the enterprise resource planning (ERP) system [18], [19], [20]. However, previous studies on the field of management accounting have not considered the change of MAs role and competencies through the I4.0 and digitalization phase [13], [20], [21]. Current studies on changing competences by I 4.0 have not undertaken the exact study about the impact of management accounting so far [1], [11], [12]. A question which has only been inadequately addressed in theory and practice is to what extent the job profiles and competences required for digitization also correspond to the field of management accounting. Compared with other methods such as case studies, surveys, archival research and experiments, the triangulation approach of this study allows us to answer and validate the research questions with the help of various sources. Since the role of MA is mainly driven by the utilization of data and the I4.0 is based on the topic data, a direct impact through the I4.0 phase on the role of MAs could be assumed. For this reason, this paper provides an overview of the results of an exploratory job advertisement analysis, which covers job advertisements from job portals for German DAX30 companies. In the course of this study, we analyzed the relevance of the concepts of competencies and I4.0 in the labor market and which job profiles are in demand in this context. Therefore, we address this research gap by identifying competencies for I4.0 focusing on the management accounting area. This study aims to further develop the understanding of the role of MAs through the influence of I4.0 to address current and future MAs. Besides that, this study also aims to broaden our knowledge of MAs relationships with other actors within the firm, especially data scientist and IT employees. Our research addresses the following research questions:

RQ1: Which competencies of MAs are affected through I4.0?

RQ2: How is the role of MA changing?

In section 2, we first take a look at the special features of I4.0 and outline the status of digitization in management accounting. Subsequently, in section 3, we present our methodological approach to answer the research questions. On the basis of the results of our qualitative and quantitative analysis, the competencies of MA will be analyzed in connection with I4.0 in management accounting, and the development of the role of MAs. In section 5, the results and recommendations for further research are discussed. 


\section{Background}

\subsection{Role of Management Accountants}

Management accounting is an essential part in any organization's activities and involves partnering in management's decision making, devising planning and performance management systems, and provides expertise in financial reporting and control in order to assist management in the formulation and implementation of an organization's strategy [24]. Information of MAs will enable internal users to make decisions effectively and contribute to the improvement of the efficiency and effectiveness of existing operation. Management accounting has evolved from focusing on cost determination and financial control to creation of value through effective use of resources [1]. Thus, the roles of MAs have also changed in line with the changes in management accounting techniques [25]. Nowadays, much of MA's role has shifted towards supporting the manager's decision, anticipating the information needs [27], acting as organization's internal business consultants and getting involved in multi-functional team [28]. It is clear that MAs are also required to understand operational processes together with the need to embed management accounting systems within operational activities [29].

\subsection{Digitalization in Management Accounting}

I4.0 is one of the ten future projects of the High-TechStrategy 2020 action plan that was announced the first time by the Federal Government and also known as the fourth revolution, in 2011 [1]. It should be noted that the term I4.0 is widespread in German speaking countries. However, similar concepts and visions are often used under another term in the international context. For instance, I4.0 is known by the term "industrie du futur" in France, or "Industrial Internet" [23] as well as further similar concepts such as "Internet of Things" or "Smart Factory" in the international context [2]. All these concepts include the use of automation, real-time, sensors and further modern technologies to transform business processes and therefore achieve a business value, however they slightly differ from one another in various aspects. For the purpose of this study we refer to I4.0 as a German concept with regards to the definition presented in the introduction. Due to the rapid development of information systems, more and more data is available in companies' MA departments [30]. Today's decision-makers are often faced with the problem of the amount of information in the reports [31]. In industrial practice, the "time-to-market" indicator becomes a competitive success factor [33]. In the context of I4.0, changes in existing data sources, access to previously unavailable data sources, and new methods of analysis arise for management accounting. In particular, science is concerned with the question of the collaboration between management accounting and digitization, and how ultimately appropriately configured business models can be completely transformed by this development.

\section{Methodology}

\subsection{Literature Analysis}

To provide an overview of the current state of science, a traditional literature review was carried out [33]. The traditional literature review serves the purpose of generally describing the extant research including methods, populations, and findings. Therefore, traditional literature review was selected to provide interesting insights based on the findings about competencies in research [35]. In order to be able to derive a well-defined definition of the I4.0 concept, a search for publications on $\mathrm{I} 4.0$ in relation to management accounting is being conducted. Following the guidelines of Webster and Watson [42] we searched by using the keywords: "Industrie 4.0"; "Industry 4.0", "Digital Transformation", "Internet of Things", "IoT" and combined each of them with the keywords: "competence", "competency", "skill"; "controlling", "controller", "management accountant" and "data scientist". Here, it is important to point out that the title of the "management accountant" in Germany is equated with the term "controller". The chosen databases were ACM Digital Library, Springer and Ebsco Business Source Complete because they cover publications from the Information Systems and Management Accounting. All the hits were first screened based on the title and abstract. In a second phase, the whole articles were screened. Articles that did not include concrete competencies were excluded from our analysis. By following the recommendations of Webster and Watson, a backward and forward search was also conducted from the analyzed articles [34]. We had a total of 2330 hits in the database search. Here, the articles were sorted by relevance and the first 25 hits for each search string were screened. After the first screening 47 articles from the databases remained for further analyses, due to excluding those articles missing the topic of competencies in combination with I4.0 and management accounting in the titles or abstracts. Only articles explicitly focusing on the mentioned competencies were chosen. At the end a total of 12 articles that research competencies for I4.0 
or similar concepts such as IoT, were selected for further analysis (cf. section 4.1). From each article we extracted the mentioned competencies and built a literature overview. Due to the fact that the development of the skills of MAs through I4.0 is a relatively unexplored area, hardly any scientific publications exist on this topic. We deliberately also refrained from any further results (for example by date, search in the title, etc.) in order to obtain as many results as possible. The restriction on Germany as research field is interesting, since Germany is the second leading nation in the topic I4.0 [22].

\subsection{Experts Analysis}

Since the topic I4.0 and management accounting as well as the related role changes is a theoretically poorly ordered and empirically under-researched subject of research, it was decided against a quantitative survey and evaluation method with subsequent testing of hypotheses. For this purpose, a survey was selected by semi-standardized interviews as a primary data collection tool. For evaluating and extending the literature review, we conducted interviews based on Glaeser and Laudel [36]. An intensity criterion and a homogeneity criterion has been defined, which each expert who is eligible for the survey must fulfill. In addition, two criteria were defined to guarantee the highest possible heterogeneity of the final sample. To meet the intensity criterion, all employees must work in the area of management accounting and have a field of activity in reporting. The reason for this is that this leads to a better explanation of the development of IT and accounting processes through standardization and automation, as they are actively involved in this development. The selected experts are working in management accounting and possessing well-founded knowledge in reporting, which make them able to give relevant insights for the participation in the investigation. With regard to the homogeneity criterion, a restriction of the experts to manufacturing companies was laid. The interviewed experts are working in the manufacturing industries. ${ }^{1}$ The manufacturing industry is currently the leading industry in I4.0 [22]. Due to the rapid technological developments in manufacturing, innovation is essential to the success of these companies and their existence on the market. To maintain sustainable innovation, manufacturing companies are demanding the ability to be proactive and profitable in their production. Thus, it can be assumed that MAs in this industry affected by the changes in their activities.
Furthermore, two criteria were introduced to ensure the highest possible heterogeneity of the interviews. The heterogeneity criterion includes that the MAs, who are being interviewed, differ in their professional experience from each other. This criterion was meant to obtain heterogeneous perspectives and knowledge of MAs from different disciplines. Potential interviews were identified in the context of the publicly available information on the website "www.vdma.org". The methodical structure of the interview guide, based on the study by Laforest and Bouchard, was designed to collect general information about the competences and tasks of MAs [36]. We relied on semi-structured interviews, which allow for in-depth exploration and are deemed a vital instrument of case research [36]. Overall, interviews with six experts from the practice were conducted as part of the data collection. In addition to the criteria of expert selection, a decision on the number of interviews to be examined is made when selecting the examination design. In the literature, a benchmark of four to ten interviews to be included in the analysis is recommended. It should be so many interviews recorded until a representative statement and thus a theoretical saturation occurs [52]. For this reason, the integration of other experts would provide little or no new input. For the follow-up, the recorded interviews were first transcribed [36]. Referring to Yin's second recommendation, we built up a managed contact database in Microsoft Excel ${ }^{1}$ for the case selection phase and a scientific research database in MAXQDA afterwards to manage audio, text and meta data. We coded the script with an inductive code approach. This means we took the competencies from the literature as codes and started coding the transcripts. The coding was performed by one researcher. The codes were lastly compared, and the differences were discussed.

\subsection{Job Advertisement Analysis}

An analysis of job advertisements allows an examination of the development of the tasks in the area of MA in practice and can thus be oriented by the longitudinal direction. In order to answer the research questions an exploratory job advertisement analysis has been carried out for the DAX30 companies. DAX30 companies were selected as they have more opportunities to invest in such potentials as digitization due to their increased investment volume. The data set for this analysis was established by periodically crawling the enterprise job portals of all DAX30 companies and covers the period from 6-25-

\footnotetext{
${ }^{1}$ Cf. additional figures and data: https://tinyurl.com/HICSS19-Results
} 
2014 to 7-13-2017. Over this period of more than three years, a total of 398,569 job openings was collected. From this data set, German-language job openings were extracted, duplicated and training positions were removed. As a result, $n=75,455$ job vacancies were derived which address regular employments within the DAX30 companies. Within this data set, 1,923 positions $(2.55 \%)$ articulate controlling positions, which were identified by analyzing the job title (e. g., by use of filtering terms like controller, controlling, which are equated to "Management Accountant" or "Management Accounting"). This document collection was analyzed by use of exploratory text mining methods:

- The job titles of the job advertisements were analyzed in order to detect dominant job profiles in the professional area of controlling (e.g., project controller, medical controller, IT-controller).

- In order to identify relevant competencies, the substantives were extracted from the job descriptions by use of part-of-speech-tagging techniques. These substantives were analyzed to derive relevant soft skills (e.g., flexibility, professional experience) and hard skills (e.g., certain software products, software brand names and programming languages).

- Additionally, a correlation analysis was carried out in order to derive typical tasks for controlling positions. For instance, controlling positions are predominantly coined by tasks like analysis, planning and decision (making).

\section{Results}

\subsection{Literature Review}

In view of the changing professional profiles, the question arises which skills and competencies controllers must have in the future and how their requirements profile changes through the introduction of digitalization in management accounting. ${ }^{2}$ Schaeffer and Weber are discussing the challenges posed by digitalization, and the thesis that the number of MAs will decline significantly in the coming years [6]. The role of the MAs will also change fundamentally, and the MA will be decentralized. Likewise, the MA will take advantage of digitalization within the enterprise, e.g. through simulations of the planning phases, but also encourage themselves to accompany them critically, in order to distinguish themselves from the newly professional area "Data Scientist" [6]. Pickard and Cokins claim that MAs have so far barely developed competences to track down strategic relationships from the self-generated data [38]. Technological progress with new tools would make it possible to prepare better decisionmaking bases [39]. In this context, studies argue that the CFO area will have to work even more closely with the CIO department in order to use Big Data and Analytics tools more efficiently [40], [41]. Gaensslen et al. explicitly point to emerging knowledge in the areas of statistics and information technology, social and communicative skills as well as a solid understanding of the business [42]. More specifically, Seufert and Oehler describe the statistical method competencies (i.e. regression, time series or clustering), which will be needed for MA in order to isolate themselves from new occupational area such as the Data Scientist [43]. In the course of the growing importance of Big Data as an analyst and information specialist, the plant MA will be increasingly active in the field of data scientist and data mining [44]. As new digital evaluation programs will automate many tasks in classical accounting, the future focus of the work of the plant MA will be on the forefront of Forecasting and Predictive Analytics [40]. Horvath and Aschenbruecker underline the necessity of predictive analysis and the creation of a data scientist, which, unlike the MA, focuses on analyzing Big Data to improve decisions [46]. In the literary analysis, moreover, it has to be stated that many authors identified different requirements for MAs with regard to IT competences. In the development of the various roles, a shift from the analyst to the business partner is shown, which is accompanied by an increase in competence requirements [46].

\subsection{Expert Review}

The participants in the survey have shown that the topic of I4.0 is in the initial stage of the respective company. The field of management accounting has experienced a major change with the introduction of the SAP system. The most mentioned competencies before the introduction of I4.0 were utilizing MS Excel. Before I4.0 appeared, the biggest part of the monthly tasks was focusing on validating data and creating reports, which were built through SAP or/and Excel. Each interviewer mentioned the ERP system as a system to collect and provide information without requiring the explicit effort of MAs. "Collecting information from the ERP system in order to then create reports in the monthly closing, which are sent to the senior management." (Interview 6). The main reason for establishing I4.0 was based on increasing transparency and optimizing the management

\footnotetext{
${ }^{2}$ Cf. additional figures and data: https://tinyurl.com/HICSS19-Results
} 
accounting processes through automation of IT systems. Besides that, there is a gain of efficiency through exchange of real time data with the production department. The participants are predicting cost savings caused by job reduction and potential revenue through competitive advantages. Instead of utilizing and spending time in reporting, time for analyzing and interpret will increase. Through direct connection to the manufacturing, data sharing and communication will also increase. In order to meet the requirements, the interviewees highlight a change in MA roles regarding soft skills, more business partnering and exchange of data. As shown in the results overview, Expert 1 explained that "they need a lot more data knowledge or data analysis skills, but also the soft skills that help to communicate with the management to drive change processes." (Interview 1). In addition to that there were assumptions regarding upcoming competencies in statistical methods. "In management accounting in the coming years, we will mainly have two types of MAs: on the one hand the MAs, who are really the data analysts and have in-depth data knowledge and work statistically, and on the other hand the MAs that are very close to the business and along with the management control processes." (Interview 1). Besides that, being the gatekeepers of the firm's information base also strengthened the position of MAs as producers of "single source of truth". "Nevertheless, we continue to use our data source from the finance team to manage the company as a whole." (Interview 5). Compared to the literature we could add IT competencies that were mentioned in the interviews but have not been found in literature, as e.g. data analytics and statistical methods.

\begin{tabular}{|c|c|c|c|c|c|c|c|}
\hline $\begin{array}{l}\text { Competence } \\
\text { Field }\end{array}$ & Topics & 1 & 2 & 3 & 4 & 5 & 6 \\
\hline Job Position & & MA & $\begin{array}{c}\text { Production } \\
\text { MA }\end{array}$ & $\begin{array}{l}\text { Sr. } \\
\text { MA }\end{array}$ & $\begin{array}{c}\text { Production } \\
\text { MA }\end{array}$ & $\begin{array}{c}\text { Production } \\
\text { MA }\end{array}$ & $\begin{array}{l}\text { Finance } \\
\text { Manage }\end{array}$ \\
\hline $\begin{array}{l}\text { Experience in } \\
\text { Management } \\
\text { Acocunting }\end{array}$ & & $3,5 \mathrm{Y}$ & $1 \mathrm{Y}$ & $9 \mathrm{Y}$ & $5 Y$ & $5 Y$ & $8 Y$ \\
\hline & Data Warehouse & $x$ & $\bar{x}$ & & $\bar{x}$ & $\bar{x}$ & $\bar{x}$ \\
\hline Competences & Progamming softwares & & $x$ & & & & \\
\hline 해 & $\begin{array}{l}\text { MA needs more IT } \\
\text { Competencies skills }\end{array}$ & $x$ & $x$ & & & $x$ & $x$ \\
\hline \multirow{4}{*}{$\begin{array}{l}\text { Technical and } \\
\text { nethodological } \\
\text { competences }\end{array}$} & $\begin{array}{l}\text { Change from traditional } \\
\text { Excel to more statistical/ } \\
\text { analytical Methods }\end{array}$ & $x$ & & & $\mathrm{x}$ & $\mathrm{x}$ & $\mathrm{x}$ \\
\hline & Utilizing of Analytics tools & $x$ & & & $x$ & $x$ & $x$ \\
\hline & $\begin{array}{l}\text { Coding and data } \\
\text { warehouse programs }\end{array}$ & & & & $x$ & & $x$ \\
\hline & $\begin{array}{l}\text { MA needs additional } \\
\text { technical and } \\
\text { methodological skills in } \\
\text { order to fullfill the } 14.0 \\
\text { requirements }\end{array}$ & $\mathrm{x}$ & & & $\mathrm{x}$ & $x$ & $x$ \\
\hline \multirow[t]{2}{*}{ Soft Skills } & $\begin{array}{l}\text { MA needs additional soft } \\
\text { skills in order to fullfill the } \\
\text { I4.0 requirements }\end{array}$ & $x$ & $x$ & $x$ & $x$ & $x$ & $x$ \\
\hline & Business Partnering & $\mathrm{x}$ & & $\mathrm{x}$ & $\mathrm{x}$ & & \\
\hline
\end{tabular}

Figure 1. Results of Expert Interviews Review.

\subsection{Job Advertisement Review}

The analysis of the job advertisements of the DAX30 companies shows a general tendency towards the development of digitalization in management accounting: Within the controlling positions, the search term digitization only occurs rarely $(n=6$ job descriptions) in the first 17 months (July 2014November 2015). By contrast, in the last 12 months (July 2016-June 2017), the term digitization occurs in 42 job descriptions. The density of job advertisements for MA in relation to all job positions stayed stable from an average of 2.8pp in 2014 to 2.9pp in 2017. In the development of professional areas in management accounting, however, hardly any changes are discernible. Only the job profile "IT MA" shows a positive development from 15 hits versus 23 hits. Likewise, the evaluation of the task profiles of MAs resulted in a change which was only rarely occurring a few times. Especially tasks from the beginning of this data collection like "Planning" $(-0.8 \%)$ and "Reporting Creation (Reporting)" (-0.5\%) have less hits in comparison to the latest job data collection. On the other side tasks like "Decision" $(+1.0 \%)$ or "Budget" $(+1.1 \%)$ show in the allocation of MAs tasks a slight increase. In the development of soft skills, positive development could be found regarding "communications skills" $(+0.9 \%)$ and "sure appearance" $(+0.7 \%)$, while "load-bearing capacity" has shown a negative development $(-1.3 \%)$. These numbers do not reflect the general increase or decrease of search terms, but the distribution of each task. This distribution is calculated as a proportion to the total occurrence of MA tasks. ${ }^{3}$ Regarding to the IT competencies of the MAs, an increase of 1,440 to 1,538 hits in the number of job advertisements can also be recorded. These are particularly evident in IT competencies with respect to MS Excel (increase of $18 \%$ ), Visual Basic (VBA) (increase from 18 to 35 hits, $94 \%$ ), and the use of SQL (increase of $31 \%$ ). The allocation of the IT competencies to the total value in the respective period reinforce this statement. The allocation of MS Excel (+1.4\%), while SAP ERP/R3 $(-1.1 \%)$ has decreased. However, as mentioned above, a significant increase can be found in IT future topics such as "Digitization" or "Automation" within the management accounting positions. For instance, the search term "Automation" showed an increase from 10 hits to 42 hits. With search terms such as "Data Science" or "Big Data", no significant increase is observable within the management accounting positions. Therefore, the frequencies of these search

\footnotetext{
${ }^{3}$ Cf. additional figures and data: https://tinyurl.com/HICSS19-Results
} 
terms within all positions of the DAX30 companies were analyzed.

\section{Synthesis of Results and Discussion}

In our research, we analyzed different sources to investigate the potential future role of MAs and their needed competencies. In general, the requirements as MA are in the beginning of a transformation phase and new competencies and requirements could appear. Especially the ability of I4.0 to analyze data and apply statistical methods is new and makes a contribution to research. Our research emphasizes the importance of changes in MAs competencies to successfully get through the transformation towards I4.0. The results of this study lead to six propositions:

Proposition 1: The technological progress is changing the relation between updating reports versus analyzing figures.

The analysis of the interviews demonstrates that, despite the early stages of I4.0, automation and standardization in the area of Management accounting took place. Especially technical tasks are exposed to this transformation, declining more and more, whereas data analysis tasks take now majority of the working time. Increasing the number of search terms associated with MAs such as those in 4.3. mentioned IT competencies ${ }^{4}$ as well as IT future topics ${ }^{5}$ confirms the statement from the interviews, whereby MA activities are increasingly automated.

Proposition 2: There is a shift from traditional analysis methods towards statistical analysis methods

This shift is mainly caused through the old perspective of retrospective information, towards statistical analysis methods. Those are meant to identify correlation in data to improve processes and products [44]. If this adaptation is successful, it will be possible for the MAs to create analyses more quickly and to derive appropriate management recommendations. This could lead to alternative planning and management approaches and become more prominent. Such individualized production and process control is based on Forecasts and Predictive Analytics, which will not only make it possible to identify changes in the market at an early stage, but also to anticipate changes [45].

Proposition 3: Current IT competencies of MAs do not meet the requirements of the potential of I4.0

To achieve the goal of a transparent and optimized management accounting process, IT systems must be automated in relation to production. Additional IT knowledge as upcoming requirement for the change through I4.0 was mentioned in the interviews. Especially deep knowledge with set up and interpretable data and databases will be important as data will grow. However, this leads to a need of methodological and professional competences as well as a thorough understanding of the relationships. Especially the article of Pickard and Cokins resulted in the thesis, that MAs have so far barely developed competences to track down strategic relationships from the self-generated data [38]. Gaensslen explicitly points to emerging knowledge in the areas of statistics and information technology [42]. In general, 6 of the 12 investigated papers have mentioned an urgent need of more IT competencies [38], [41], [42], [43].

Proposition 4: The demand of the data scientist is increasing, but not substituting the MA.

The analysis of job advertisements showed evidence that the demand for Data Scientist is increasing. However, there was not sufficient evidence that there is a positive relationship between MA and data scientist. Thus, we can conclude that the job of a Data Scientist will develop independently from that of a MA. The results in 4.3. show that the demand for MA stays on a constant level over the last three years, while on the same time the demand for Data Scientist is increasing. Nevertheless, it is not clarified whether all of the competencies (e.g. coding) we have discussed in the interviews will necessarily get required competencies of MAs. Instead there is the emerging role of a Data Scientist, which was also mentioned in the literature as well as in the interviews. Statements by some authors [6] regarding the reduction of the MA density due to the digitization can at least be weakened, as the job advertisements have remained at the same level within the period under review. The interviews also pointed out that MAs are even closer to the business in the future and, together with the management, administer the control processes.

Proposition 5: Data Scientist will support and set up the basis for $M A$

In order to meet these challenges, the work of management accounting can no longer rely solely on retrospective analyzes. Here the data scientist can be used to evaluate data based on real-time and thus to create a database that provides management with a comprehensive picture of the company's situation. As a digitized and automated production system will be difficult to grasp, direct observations will be limited so that analyzes will, among other things, take place through the interpretation of data.

\footnotetext{
${ }^{4}$ IT Competencies: MS Excel, Visual Basic (VBA), SAP and SQL
} 


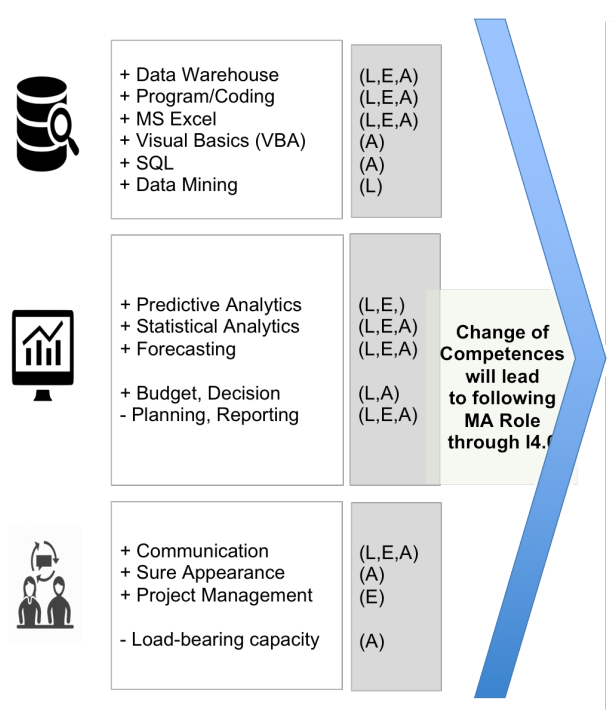

Figure 2. The changing role of the MAs.

\section{Proposition 6: There is a shift in MA's role to stronger business partnering.}

Since the Data Scientist will create and set up the data, the information must be interpreted and exchanged within the company [6], [39], [40], [42]. In order to meet these requirements, MA is facing more in the role of the proposer of decisions and measures. In all interviews, the necessary increase in the soft skills of MAs was addressed (Interview 1-6). Fig.2 shows the change of competencies and the new role of MA through I4.0.

The Results are based on $\mathrm{L}=$ Literature Review, $\mathrm{E}=$ Expert Interviews, $\mathrm{A}=$ Analysis of Job Advertisements.

\section{Conclusions, Limitations and Future Development}

This paper provides theoretical as well as practical contributions to the change of the MA role through the I4.0. However, the boundaries of the work are not to be disregarded and should be presented as links for future research in this field. The relationship between the activities of MAs and future applications such as forecasting, early detection and scenario analyses were not fully investigated. For this reason, the work can only be an initial recording and classification of the current MA role in the context of the I4.0. Furthermore, the work offers a limited generalizability with regard to the size of the company, since only DAX30 companies were selected on the basis of the investigation field. Typically, large companies are the "early adopters" of new technologies or the leaders. Small and medium-sized enterprises (SMEs), on the other hand, are much more hesitant. They often do not have the right specialists and budget to implement technology projects and cannot afford to make mistakes. Concerns about IT security could be obstacles for investing in digitization, especially among SMEs. Likewise, the analyzed view provides potential for further research over more years. Also, the case study number was low with six MAs as experts, in order to be able to make a very significant statement regarding the results. This leads to a limited depth of this work. To complete the results further research and especially investigation of data of tech companies would be helpful, since this paper has analyzed companies, which were currently faced in an early phase of I4.0. We acknowledge that further research in the area of management accounting roles and change through the I4.0 is required to study further aspects of competencies as well as define how the MA role could change in future practice. Especially implementation of variables as "performance" or "organizational structure" could explain a certain development. Empirically there are repeated measurements or a long-term case study in which the effects in management accounting systems are investigated. Future studies could be instructed out of the described limitations. Moreover, we mentioned that concerning its regulation, the German management accounting profession differs from other countries such as the UK or the USA. Although some research on German management accounting and the German management accounting profession has already been carried out [48], [49], how the German management accounting profession in relation to upcoming IT development actually emerged and developed is still under-researched. A lot has been written about the accounting profession in other countries [50], [51]. To complement this stream of 
literature, future research can broaden our knowledge of the changing role of German accounting profession. In addition to that, an investigation of the current digitalization and new internet technology phase in relation to the changing role of MAs in other countries could be interesting. We acknowledge, that further research in the area of I4.0 competencies is required to study further aspects of competencies as well as define how the changing competencies could be applied in practice. Especially a definition of a competency profile for a certain job description, e.g. which competencies of the model should a data scientist bring, could be a further interesting point for research and practice. Overall, we argue that there is still a need for research on what MAs do after I4.0 is fully integrated in companies and the appearance of data scientist is widespread within companies.

\section{References}

[1] H. Kagermann, W. Wahlster, J. Helbig, "Umsetzungsempfehlungen für das Zukunftsprojekt Industrie 4.0”, Frankfurt/Main, 2013.

[2] A. Roth, "Industrie 4.0 - Hype oder Revolution?" In: Roth, A. (ed.) Einführung und Umsetzung von Industrie 4.0, pp. 1-15. Gabler Verlag, Berlin, 2016.

[3] D. Buhr, "Soziale Innovationspolitik für die Industrie 4.0." Expertise im Auftrag der Abt. Wirtschafts und Sozialpolitik der Friedrich-Ebert-Stiftung, Bonn, 2015.

[4] PwC AG WPG, Digital Controlling. Digitale Transformation im Controlling, https://www.pwc.de/de/digitale-transformation/assets/pwcstudie-digitale-transformation-im-controlling.pdf" (2015),

[5] H. Jodlbauer and S. Strasser, „Geschäftsmodellinnovation basierend auf Industrie 4.0 sichern den zukünftigen Erfolg der Unternehmen.”, in: Der Controlling Berater. Band 43, Haufe, 2016, p.109-122,

[6] U. Schäffer and J. Weber, "Controlling im Wandel - Die Veränderung eines Berufsbilds im Spiegel der zweiten WHU-Zukunftsstudie", Zeitschrift für erfolgsorientierte Unternehmenssteuerung, 27 (3), 2015, p. 185-191.

[7] R. Sauter, M. Bode and D. Kittelberger, "Auswirkungen von Industrie 4.0 auf die produktionsnahe Steuerung der Wertschöpfung", in: Controlling - Zeitschrift für erfolgsorientierte Unternehmensteuerung, 27. H. 8/9., 2015.

[8] E. Roßmeissl and R. Gleich, "Industrie 4.0 Herausforderungen für das Produktionsmanagement und controlling", in: Horváth/Michel (Hrsg.), Controller Agenda 2017, 2017, p. $23-35$.

[9] C. F. Frey and M. A. Osborne, "The Future of Employment: How Susceptible are Jobs to
Computerisation",http://www.oxfordmartin.ox.ac.uk/downl oads/academic/ The_Future_of_Employment.pdf, 2012.

[10] S. Erol, A. Jäger, P. Hold and W. Sihn, "Tangible Industry 4.0: a scenario-based approach to learning for the future of production." In: Conf. on Lear. Fact. Gjøvik, 2016, pp. 1-6. Norway.

[11] Acatech, Fraunhofer Institut für Materialfluss und Logistik, equeo $\mathrm{GmbH}$, "Kompetenzentwicklungsstudie Industrie 4.0”. Report, 2016.

[12] L. Prifti, M. Knigge, H. Kienneger and H. Krcmar, "A Competency Model for Industrie 4.0 Employees", in: MKWI 2017, 2017.

[13] S. Byrne and B. Pierce, "Towards a More Comprehensive Understanding of the Roles of Management Accountants.", in: European Accounting Review, 16, 2007, pp. 469-498.

[14] J. Järvinen, "Shifting NPM Agendas and Management Accountants' Occupational Identities." Accounting, Auditing \& Accountability Journal, 22, 2009, pp. 1187

[15] J. E. Sorensen, "Management Accountants in the United States: Practitioner and Academic Views of Recent Developments", in: Chapman, C. S., Hopwood, A. G., Shields, M. D. (Eds.), Handbook of Management Accounting Research. Amsterdam, 2009, pp. 1271-1296.

[16] F. A. Kennedy and J. E. Sorensen, "Enabling the Management Accountant to Become a Business Partner": Organizational and Verbal Analysis Toolkit. Journal of Accounting Education, 24(4), 2006, pp. 149- 171.

[17] H. Yazdifar and M. Tsamaney, "Management Accounting Change and the Changing Roles of Management Accountants: A Comparative Analysis Between Dependent and Independent Organizations", in Journal of Accounting and Organizational Change, 1(2), 2005, pp. 180-198.

[18] A. O' Mahony and J. Doran, “The Changing Role of Management Accountants; Evidence from the Implementation of ERP Systems in Large Organizations", International Journal of Business and Management, 2008.

[19] M. Granlund and T. Malmi, "Moderate impact of ERPs on management accounting: a lag or permanent outcome", in: Manage Account Res, 13, 2002, pp. 299-321.

[20] D. Emsley, "Restructuring the Management Accounting Function: A Note on the Effect of Role Involvement on Innovativeness." Management Accounting Research, 16, 2015, pp. 157-177.

[21] J. Mouritsen, "Five Aspects of Accounting Departments' Work.” Management Accounting Research, 7, 1996, pp. 283-303.

[22] bitcom, VDMA: Implementation Strategy Industrie 4.0. Report, bitcom, ZWEI, 2016. 
[23] I. Grangel-González, L. Halilaj, G. Coskun, S. Auer, D. Collarana and M. Hoffmeister, "Towards a Semantic Administrative Shell for Industry 4.0 Components.”, 2016.

[24] J. Gebhardt, A. Grimm and M. Neugebauer, "Developments 4.0 Prospects on future requirements and impacts on work, vocational education”, 2015, pp. 117-133.

[25] P. Horvath and A. Aschenbrücker, "Data Scientist: Der Data Scientist - neue Potentiale für den Controller?" in: Controlling im digitalen Zeitalter 2015. pp. 45-49.

[26] M. Talha, J. Raja and A. Seetharaman, “A New Look at Management Accounting", Journal of Applied Business Research, vol. 26, iss. 4, 2010, pp. 83-95.

[27] G. Siegel and J. Sorensen, "Counting More, Counting Less: Transformations in the Management Accounting Profession", Institute of Management Accountants, 1999.

[28] A. O. Janet, "Management Accounting Practices in Nigerian Companies", Working Paper Series: Department of Economics, University of Ibadan, Nigeria, 1998.

[29] S. Rabino, "The accountants' contribution to product development teams - a case study". Journal of Engineering and Technology Management, 18(1), 2001, pp. 73-90.

[30] W. Gladen, Performance Measurement: Controlling mit Kennzahlen, 6. Aufl., Wiesbaden, 2014.

[31] R. Ewert and A. Wagenhofer, Interne Unternehmensrechnung, 7. Aufl., Frankfurt, 2008.

[32] A. Uçaktürk and M. Villard, "The Effects of Management Information and ERP Systems on Strategic Knowledge Management and Decision-Making". ProcediaSocial and Behavioral Sciences, 99, 2013, pp. 1035-1043.

[33] R. Obermaier, Industrie 4.0 als unternehmerische Gestaltungsaufgabe. Wiesbaden: Springer Gabler, 2016.

[34] J. Webster and R. Watson: "Analyzing the Past to Prepare for the Future: Writing a Literature Review". In: Management Information Systems Quarterly, 26, 2002.

[35] M. Massaro, J. Dumay and J. Guthrie, "On the shoulders of giants: undertaking a structured literature review in accounting", Accounting, Auditing \& Accountability Journal, Vol. 29 No. 5, pp. 767-801. 2016

[36] J. Laforest, "Safety diagnosis tool kit for local communities. Guide to organizing semi-structured interviews with key informants", Quebec: Institut national de sante publ., 2009.

[37] R. K. Yin, "Case Study Research: Design and Methods", Fourth Edition. Thousand Oaks Zahra, 2009.

[38] M. D. Pickard, and G. Cokins, "From bean counters to bean growers: Accountants as data analysts - a customer profitability example". Journal of Information Systems,29(3), 2015, pp. 151-164.
[39] ICV Ideenwerkstatt, "Industrie 4.0 - Controlling im Zeitalter der intelligenten Vernetzung", 2015.

[40] R. Sauter, M. Bode and D. Kittelberger, "Auswirkungen von Industrie 4.0 auf die produktionsnahe Steuerung der Wertschöpfung", Zeitschrift für erfolgsorientierte Unternehmensteuerung, 27. Jg. H. 8/9., o. S, 2015.

[41] K. Groenke and J. Helmel, "Big Data im CFO-Bereich - Kompetenzanforderungen an den Controller", Gleich, R./Klein, A., in: Controlling und Big Data Special, Freiburg/München, 2015, p. 123-140.

[42] S. Gänßlen, H. Losbichler, R. Niedermayr, L. Rieder, U. Schäffer and J. Weber "Die Kernelemente des Controllings: Das Verständnis von ICV und IGC", in: Controlling \& Management Review, 57 (3), 2013, p. 56-61.

[43] A. Seufert and K. Oehler, "Controlling und Big Data: Anforderungen an die Methodenkompetenz", In: Schäffer U., Weber J. (eds) Controlling \& Management Review Sonderheft 1-2016. Springer Gabler, Wiesbaden, 2016.

[44] G. Reischauer and L. Schober, "Industrie 4.0 durch strategische Organisationsgestaltung managen", in: Obermaier, R. (Hrsg.): Industrie 4.0 als unternehmerische Gestaltungsaufgabe, Wiesbaden, 2016.

[45] P. Mertens, "Industrie 4.0 - Herausforderungen auch an Rechnungswesen und Controlling im Überblick", in: Controlling - Zeitschrift für erfolgsorientierte Unternehmensteuerung, 27. Jg., 2015, H. 8/9., 2015.

[46] R. Gleich, P. Thiele and J. C. Munck, "Auswirkung von Industrie 4.0 auf das Produktionscontrolling von morgen", Controller Magazin, 41(3), 2016, pp. 78-82.

[47] P. Horvath and A. Aschenbrücker, "Data Scientist: Der Data Scientist - neue Potentiale für den Controller?" in: Controlling im digitalen Zeitalter - Herausforderungen und Best-Practice-Lösung, 2015, pp. 45-49.

[48] A. Becker and M. Messner, "After the Scandals: A German-Speaking Perspective on Management Accounting Research and Education". European Accounting Review, 14, 2005, pp. 417-427.

[49] R. Luther, T. C. Jones, T. C. and A. Saxl, "Experiencing Change in German Controlling: Management Accounting in a Globalizing World.” Amsterdam: CIMA. 2010.

[50] D. J. Cooper and K. Robson, "Accounting, Professions and Regulation: Locating the Sites of Professionalization." Accounting, Organizations and Society, 2006, pp. 415-444.

[51] J. R. Edwards and S. P. Walker, "Accountants in Late 19th Century Britain: A Spatial, Demographic and Occupational Profile." Accounting \& Business Research, 37, 2007, pp. 63-89.

[52] S. Lamnek, (1993): Methoden und Techniken. Qualitative Sozialforschung (Band 2), 2.Auflage, Benz, Weinheim., pp. 102. 